\title{
Experimental Study on the Temporal and Spatial Variation Law of Gas Flow in Different Rock Pillar Drainage Boreholes
}

\author{
ZHonghua Wang ${ }^{1,2, *}$ \\ ${ }^{1}$ National Key Laboratory of Gas Disaster Detecting, Preventing and Emergency Controlling, Chongqing 400037 \\ ${ }^{2}$ China Coal Technology Engineering Group Chongqing Research Institute, Chongqing 400037
}

\begin{abstract}
In order to study the temporal and spatial variation of gas flow in different rock pillar extraction boreholes, gas pressure, gas content, gas emission from 100-meter coal holes and coal seam permeability coefficient were measured on site. The site inspected the gas flow in the boreholes at $15 \mathrm{~m}, 7.5 \mathrm{~m}$, directly above, $7.5 \mathrm{~m}$, and $15 \mathrm{~m}$ at the lower slab of different rock pillar floor roadways. It analyzed the change law of gas flow in boreholes of 710 floor lanes and 505 floor lanes, which provided a basis for the layout of gas drainage boreholes.
\end{abstract}

\section{B4 coal seam gas basic parameter test}

\subsection{Coal seam gas pressure}

This time, the pressure measurement and sealing were carried out with a grouting pump for grouting and sealing. To ensure the quality of the sealing, the whole rock section was sealed with grouting from the upward borehole. When it is estimated that the injected cement slurry is about to reach the position of the screen hole, a technician or senior skilled worker should observe whether there is a backflow phenomenon of clear water at the pressure measurement nozzle. This phenomenon is called slurry return or slurry return. If the grout return is successful, immediately stop the power supply of the hole-sealing pump and the grouting of the hole is completed. Completely close the gate valve of the grouting pipe and disassemble the high-pressure grouting pipe. After the drilling is sealed, it should be cleaned in time to prevent the cement slurry from solidifying or depositing in the grouting pump and high-pressure slurry pipe.

For upward pressure measurement boreholes, if there is water (non-pressure water) in the borehole, when the pressure measurement is finished and the pressure gauge is removed, the amount of water released from the borehole should be measured, and the hole should be sealed according to the drilling parameters The parameter calculates the hydrostatic pressure of the water in the borehole and removes it from the measured pressure.

According to coal seam development and roadway layout conditions, in accordance with the relevant provisions of the "Pressure Measurement Standard", the gas pressure is determined by the direct method, which is the grouting plugging method and the passive pressure measurement method. The measurement results are shown in Table 1.

Table 1. Gas pressure measurement result table

\begin{tabular}{|c|c|c|}
\hline Measurement location & See coal elevation $(\mathrm{m})$ & Gas pressure $(\mathrm{MPa})$ \\
\hline 710 Floor Lane & -622.5 & 2.0 \\
\hline 505 Floor Lane & -783 & 2.0 \\
\hline$-650 \mathrm{~m}$ Dongda Alley & -615 & 1.98 \\
\hline$-650 \mathrm{~m}$ West Bypass & -632 & 2.50 \\
\hline
\end{tabular}




\subsection{Coal seam gas content}

Utilize the constructed boreholes, take coal samples and use DGC gas content measuring device to directly measure the gas content of the B4 coal seam. The measurement results are shown in Table 2.

Table 2. B4 Coal Seam Gas Content Measurement Results

\begin{tabular}{|c|c|c|}
\hline Measurement location & See coal elevation $(\mathbf{m})$ & Gas content $\left(\mathbf{m}^{3} / \mathbf{t}\right)$ \\
\hline 710 Floor Lane & -622.5 & $8.99 \sim 13.79$ \\
\hline 505 Floor Lane & -746.9 & $8.28 \sim 22.45$ \\
\hline-650 m Dongda Alley & -615 & 14.64 \\
\hline$-650 m$ West Bypass & -632 & 12.52 \\
\hline
\end{tabular}

\subsection{Gas emission from 100-meter coal holes and coal seam permeability coefficient}

The survey adopts the simple drainage method, and the measured gas emission and attenuation coefficient of 100meter coal holes are $0.075 \sim 0.571$ and $0.26 \sim 0.4$ respectively. The air permeability coefficient of the coal seam is measured by the drilling radial flow method. The main steps are: first, the pressure measurement drilling is constructed in the vertical coal seam, the drilling is sealed and the original gas pressure of the coal seam is measured. When the gas pressure of the pressure measuring borehole stabilizes at the highest value, the pressure gauge is removed to reduce the pressure in the borehole to the ambient atmospheric pressure, so that the borehole naturally discharges gas, and the gas flow rate of the borehole is measured. Finally, substitute the relevant formula to calculate the coal seam permeability coefficient. Through calculation, the air permeability coefficient of B4 coal seam in Shangzhuang Coal Mine is 0.0259 0.0961.

\section{Investigation plan for gas flow in drainage boreholes}

The simple drainage method is used to test the gas flow in the borehole ${ }^{[1-5]}$. The hole diameter is $\Phi 75 \mathrm{~mm}$. The inspection sites are 710 floor roadway and 505 floor roadway. The thickness of the two roadways and the rock pillars of the overlying coal seam are $15 \mathrm{~m}$ and $19 \mathrm{~m}$, respectively. After the borehole construction, 5 survey boreholes are arranged for each survey content, namely 5 survey positions, which are $15 \mathrm{~m}$ on the lower bank, $7.5 \mathrm{~m}$ on the lower bank, directly above, $7.5 \mathrm{~m}$ on the upper bank, and $15 \mathrm{~m}$ on the upper bank. Each roadway is tested in three groups, and the specific inspection locations are shown in Table 3.

Table 3. Investigation location of gas flow in drainage boreholes

\begin{tabular}{|l|c|c|c|}
\hline \multirow{2}{*}{ Roadway } & \multicolumn{2}{|c|}{ Inspection location (from the head of the tunneling: $\mathrm{m}$ ) } \\
\cline { 2 - 4 } & The first group & The second group & The third group \\
\hline 710 Floor Lane & 139 & 95 & 55 \\
\hline 505 Floor Lane & 204 & 168 & 100 \\
\hline
\end{tabular}

\section{The law of gas emission from different boreholes}

flow in the boreholes within $15 \mathrm{~m}$ on both sides of the roof of the 710 and 505 floor lanes in Shangzhuang Coal Mine. The measurement results are shown in Tables 4 and 5, respectively.

The simple drainage method was used to measure the gas

Table 4. Measured results of gas flow in boreholes of 710 wind tunnel floor lane (unit: $\mathrm{m}^{3} / \mathrm{d}$ )

\begin{tabular}{|c|c|c|c|c|c|c|}
\hline Number of groups & Time $(\mathrm{d})$ & Lower $15 \mathrm{~m}$ & Lower $7.5 \mathrm{~m}$ & Right above & Upper $7.5 \mathrm{~m}$ & Upper $15 \mathrm{~m}$ \\
\hline \multirow{4}{*}{$\begin{array}{c}\text { Head-on 139m } \\
\text { (First group) }\end{array}$} & 1 & 5.28 & 6.25 & 14.62 & 9.14 & 5.53 \\
\cline { 2 - 7 } & 3 & 5.06 & 5.94 & 10.56 & 5.80 & 5.53 \\
\cline { 2 - 7 } & 4 & 4.57 & 5.40 & 8.64 & 4.75 & 4.75 \\
\cline { 2 - 7 } & 5 & 4.40 & 4.32 & 5.59 & 5.06 & 4.57 \\
\cline { 2 - 7 } & 6 & 3.66 & 3.55 & 4.42 & 4.10 & 3.77 \\
\hline
\end{tabular}




\begin{tabular}{|c|c|c|c|c|c|c|}
\hline \multirow{4}{*}{$\begin{array}{c}\text { Head-on 95m } \\
\text { (Second Group) }\end{array}$} & 1 & 4.75 & 5.96 & 12.03 & 7.59 & 5.21 \\
\cline { 2 - 8 } & 3 & 4.48 & 5.56 & 9.64 & 6.40 & 4.30 \\
\cline { 2 - 7 } & 4 & 3.83 & 5.32 & 7.55 & 5.67 & 3.84 \\
\cline { 2 - 8 } & 5 & 3.49 & 5.71 & 8.06 & 4.98 & 3.91 \\
\hline \multirow{3}{*}{$\begin{array}{c}\text { Head-on 55m } \\
\text { (The third group) }\end{array}$} & 6 & 3.35 & 5.00 & 6.92 & 4.79 & 3.63 \\
\cline { 2 - 8 } & 4 & 4.17 & 5.07 & 8.91 & 6.23 & 4.54 \\
\cline { 2 - 8 } & 4 & 3.77 & 4.88 & 8.31 & 6.40 & 4.30 \\
\cline { 2 - 8 } & 6 & 3.49 & 4.44 & 8.06 & 4.98 & 3.94 \\
\hline
\end{tabular}

Table 5. Measured results of gas flow in boreholes of 505 wind tunnel floor lane (unit: $\mathrm{m}^{3} / \mathrm{d}$ )

\begin{tabular}{|c|c|c|c|c|c|c|}
\hline Number of groups & Time (d) & Lower $15 \mathrm{~m}$ & Lower $7.5 \mathrm{~m}$ & Right above & Upper $7.5 \mathrm{~m}$ & Upper $15 \mathrm{~m}$ \\
\hline \multirow{6}{*}{$\begin{array}{l}\text { Head-on } 204 \mathrm{~m} \\
\text { (First group) }\end{array}$} & 1 & 3.23 & 5.66 & 13.24 & 9.01 & 3.39 \\
\hline & 3 & 2.98 & 5.90 & 8.11 & 5.35 & 2.69 \\
\hline & 4 & 2.67 & 4.77 & 9.75 & 5.79 & 2.98 \\
\hline & 5 & 2.58 & 4.11 & 8.61 & 6.30 & 2.61 \\
\hline & 6 & 2.50 & 3.29 & 6.67 & 5.58 & 2.48 \\
\hline & 7 & 2.38 & 2.97 & 8.16 & 3.64 & 2.40 \\
\hline \multirow{6}{*}{$\begin{array}{l}\text { Head-on 168m } \\
\text { (Second Group) }\end{array}$} & 1 & 3.33 & 5.36 & 11.44 & 9.01 & 4.09 \\
\hline & 3 & 2.98 & 4.90 & 10.11 & 7.35 & 3.19 \\
\hline & 4 & 2.67 & 4.77 & 9.75 & 6.79 & 1.98 \\
\hline & 5 & 2.58 & 4.11 & 8.61 & 6.30 & 1.61 \\
\hline & 6 & 2.50 & 3.69 & 7.67 & 5.58 & 1.48 \\
\hline & 7 & 1.38 & 2.97 & 8.16 & 3.64 & 1.70 \\
\hline \multirow{6}{*}{$\begin{array}{l}\text { Head-on } 100 \mathrm{~m} \\
\text { (The third group) }\end{array}$} & 1 & 3.23 & 5.26 & 9.24 & 7.01 & 3.39 \\
\hline & 3 & 2.28 & 4.90 & 8.11 & 6.35 & 2.89 \\
\hline & 4 & 1.67 & 4.37 & 7.75 & 5.29 & 2.98 \\
\hline & 5 & 1.58 & 4.11 & 6.61 & 4.30 & 2.41 \\
\hline & 6 & 1.50 & 3.49 & 6.67 & 3.58 & 2.18 \\
\hline & 7 & 2.08 & 2.87 & 5.16 & 3.24 & 2.50 \\
\hline
\end{tabular}

From Tables 4 and 5, we can see that the gas flow in the boreholes at the same observation time at different locations in the $15 \mathrm{~m}$ coal seams above the 710 and 505 floor lanes is directly above the coal seam, $7.5 \mathrm{~m}$ lower, $7.5 \mathrm{~m}$ upper, and lower. $15 \mathrm{~m}$, upper upper $15 \mathrm{~m}$, and show a trend of gradual attenuation with the passage of time, the order of attenuation is the same as the order of gas flow from large to small. It can be seen that the pressure relief effect of the coal seam above the floor roadway, from strong to weak, is directly above the coal seam, lower bank $7.5 \mathrm{~m}$, upper bank $7.5 \mathrm{~m}$, lower bank $15 \mathrm{~m}$, and upper bank $15 \mathrm{~m}$.

The initial gas flow of the boreholes in the $15 \mathrm{~m}$ coal seam on both sides of the 710 floor lane is the largest directly above, followed by $7.5 \mathrm{~m}$ on both sides, and the smallest on both sides $7.5 \sim 15 \mathrm{~m}$. The maximum values are $14.62,9.14,5.53 \mathrm{~m} 3 / \mathrm{d}$, respectively. The initial gas flow in the $15 \mathrm{~m}$ coal seam on both sides of the 505 floor lane is the largest directly above, followed by $7.5 \mathrm{~m}$ on both sides, and the smallest on both sides $7.5 \sim 15 \mathrm{~m}$. The maximum values are $13.24,9.01,4.09 \mathrm{~m} 3 / \mathrm{d}$, respectively. It can be seen that the pressure relief effect of the coal seam directly above the floor roadway is in order of $7.5 \mathrm{~m}$ and $7.5 \sim 15 \mathrm{~m}$ directly above the coal seam, on both sides. The initial gas flow rate of boreholes at the same location shows a gradual decrease from the first group to the third group. It can be seen that with the increase of the excavation time of the floor rock roadway, the amount of gas emission corresponding to the borehole gradually increases, and the pressure relief effect gradually increases.

\section{Conclusion}

Through the test, it is found that the gas pressure in the B4 coal seam of Shangzhuang Coal Mine is $1.98 \sim 6.0 \mathrm{MPa}$, the gas content is $7.04 \sim 22.45 \mathrm{~m}^{3} / \mathrm{t}$, the coal seam attenuation coefficient is $0.26 \sim 0.4 \mathrm{~d}-1$, and the gas flow 
rate of the 100 -meter borehole is $0.075 \sim 0.571 \mathrm{~m}^{3} / \mathrm{t}$. Coal seam permeability coefficient is $0.0259 \sim 0.0961 \mathrm{~m}^{2} /$ $\mathrm{MPa}^{2} \cdot \mathrm{d}$.

The order of gas emission from the coal seam above the pressure relief floor rock roadway is directly above the coal seam, $7.5 \mathrm{~m}$ lower, $7.5 \mathrm{~m}$ upper, $15 \mathrm{~m}$ lower, and $15 \mathrm{~m}$ upper. With the increase of the excavation time of the floor rock roadway, the pressure relief effect of the upper coal seam gradually increases, and the amount of gas emission corresponding to the borehole gradually increases. The initial gas flow in the borehole directly above the coal seam is the largest, the maximum is $14.62 \mathrm{~m}^{3} / \mathrm{d}$; the second is $7.5 \mathrm{~m}$ on both sides, the maximum is $9.14 \mathrm{~m}^{3} / \mathrm{d}$; the second is $7.5 \sim 15 \mathrm{~m}$ on both sides, the maximum is $5.53 \mathrm{~m}^{3} / \mathrm{d} \mathrm{d}$. The gas flow in the same relative position of 710 floor lane is greater than that of 505 floor lane.

\section{Acknowledgments}

This work was financially supported by the national key research and development program of China (2017YFC0804206), General project of Chongqing Research Institute Co., Ltd (2019YBXM31), General project of Chongqing Research Institute Co., Ltd
(2020YBXM22).

\section{References}

1. Zhang T J, Jiang X K, Bao R Y, Chen J W, Fan Y F. (2018) Analysis of gas flow attenuation characteristics of cross-layer boreholes in high gas mines J. Coal Science and Technology , 46(08): 7479.

2. Zhou R, Yan B Y, Yan X Q. (2015) Gas flow prediction technology for regional outburst hazards through boreholes J. Coal Mine Safety , 46(12): 6164.

3. Tian S X, Jiang C L, Xu L H, Tang J, Chen Yu J, Li X W, Zhang Q. (2016) Research on the law of initial gas flow in boreholes J. Coal Mine Safety, 47(05): 14$17+21$.

4. Zhou R, Liu W B. (2015) Research on the technology of borehole gas flow prediction for regional outburst hazard J. Coal Technology, 34(09): 140-142.

5. Fu Z C, Xie Z L. (2012) Analysis of the influence of borehole gas flow measurement on the attenuation coefficient[J]. Coal Mine Safety, 43(S1): 136-139. 